\title{
Lateral-torsional buckling resistance of cold-formed high strength steel rectangular hollow beams
}

\author{
Anh Tuan Tran \\ Luleå University of Technology, Luleå, Sweden
}

\begin{abstract}
Hollow sections have been widely used for steel structures. Applications of High Strength Steel (HSS) on cold-formed hollow sections lead to thinner and lighter structures. This paper presents numerical investigations on the lateral-torsional buckling resistance of the cold-formed high strength steel rectangular hollow beam. Results from finite element analysis using Abaqus software are compared to calculations accroding to Eurocode 3. First, buckling analyses are carried out to investigate buckling behaviors of the rectangular hollow beams. In this step, elastic critical moments have been investigated and compared to calculations according to SN003. Buckling shapes have been also obtained in this step. Secondly, nonlinear analyses using Riks method have been performed. Buckling resistances of the beams with various thicknesses, various high strength materials S460, S650 and S960 have been compared to calculations according to EC 3. Further investigations on geometric imperfection sensitive have been carried out with different amplitudes L/1000, L/750, L/500 and L/250.
\end{abstract}

\section{INTRODUCTION}

Resistance of beams under bending is governed by Lateral Torsional Buckling (LTB). Some studies on LTB have been presented in [1-3]. Meftah et al. have published a study on lateral buckling of box beam under combined axial and bending loads in [1]. In this paper, authors have used Ritz and Galerkin's methods to develop an analytical model. Results have been compared to calculations according to Eurocode 3. D. Sonck and J. Belis have presented investigation on lateral torsional buckling resistance of cellular beams under constant bending moment in [2]. Using finite element analysis and Eurocode 3 (EC 3) approach, authors have proposed a design approach for LTB. New design curves for lateral torstional buckling have been investigated by A. Taras et al. [3]. The authors have proposed a new formulaic description of the buckling resistance.

High Strength Steel (HSS) have been widely studying and applying on steel structures because of its advanced characteristics [4-5]. Particularly, application of HSS on cold-formed hollow sections leads to thinner and lighter structures. To supplement and get better understand of lateral torsional buckling of cold formed high strength steel hollow beam, a numerical investigation using finite element analysis program Abaqus [6] has been performed. Firstly, buckling analysis has been carried out. Elastic critical moments have been investigated and compared to calculations according to
EC 3. Buckling shapes have been also obtained in this step. Secondly, nonlinear analyses using Riks method have been performed. Buckling resistances of the beams with various thicknesses, various high strength materials S460, S650 and S960 have been compared to calculations according to EC 3. Further investigations on geometric imperfection sensitive have been carried out with different amplitudes L/1000, L/750, L/500 and L/250.

\section{FINITE ELEMENT MODELS}

\subsection{Geometry of models}

Rectangular hollow beams with end moments have been considered. Length $(\mathrm{L})$ of the beam is $6000 \mathrm{~mm}$. Dimensions at center of the beam cross section is presented in Fig. 1. The height and width of cross section are $300 \mathrm{~mm}$ and $100 \mathrm{~mm}$ respectively. Radii at the corner is $25 \mathrm{~mm}$. Various thicknesses (t) $6 \mathrm{~mm}, 8 \mathrm{~mm}, 10 \mathrm{~mm}, 12 \mathrm{~mm}, 14 \mathrm{~mm}$ have been taken into this study. Various lengths of beam have been used to construct a buckling curve of the rectangular hollow section.

\subsection{Analysis method}

In this study, buckle analysis and Geometrically and Materially Nonlinear Analysis with mperfection models (GMNIA) have been considered. Buckle analysis have been initially performed in order to get buckling shape and elastic critical 

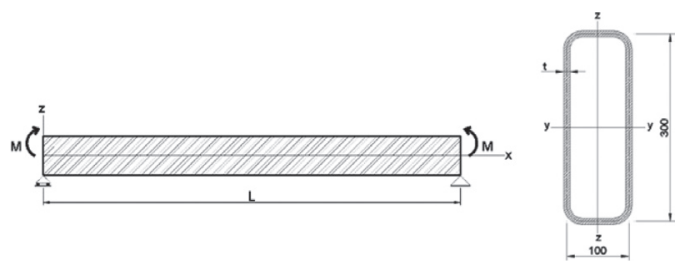

Figure 1. Geometry of beam.

moment for lateral-torsional buckling. Then, nonlinear analysis using Riks method has been carried out. The riks method has been mentioned in [7-9].

\subsection{Finite element type and mesh}

Commercial finite element analysis program Abaqus [6] has been used for the buckle analysis and the nonlinear analysis in this study. In Abaqus, there are various $3 \mathrm{D}$-dimentional solid elements such as C3D4 (4-node linear tetrahedron), C3D8 (8-node linear brick), C3D8R (8-node linear brick, reduced integration with hourglass control), C3D10M (10-node modified tetrahedron, with hourglass control). In this study, 3D-dimentional solid elements C3D8R have been used. Figure 2 presents typical FE mesh of the models.

\subsection{High strength steel materials}

With development of steel production and processing technology, High Strength Steel material (HSS) have been studying and widely applying on steel structures. Particularly, applications of high strength steel on cold-formed hollow sections lead to thinner and lighter structures. Steel grades up to S460 have been using in Eurocode 3, part 1-1 to part 1-11. Eurocode 3 part 1-12 recommend rules for steel material up to S700. In this study, high strength steel materials S460, S650 and S960 have been considered in order to investigate influences of HSS on buckling behavior of beams. The materials have been referred in [13-14] and material data at Luleå University of Technology. The Young's modulus $\mathrm{E}=210000\left(\mathrm{~N} / \mathrm{mm}^{2}\right)$, the shear modulus $\mathrm{G}=81000\left(\mathrm{~N} / \mathrm{mm}^{2}\right)$ and the Poisson's ratio $\mathrm{v}=0.3$ have been used for calculations. In abaqus, the true stress and true plastic strain are used as material characteristic. Relation between true stress and true plastics strain is defined in [6] as follows:

$$
\begin{aligned}
& \sigma_{\text {true }}=\sigma_{\text {nom }}\left(1+\mathcal{E}_{\text {nom }}\right) \\
& \mathcal{E}_{\text {true }}=\ln \left(1+\varepsilon_{\text {nom }}\right)-\frac{\sigma_{\text {true }}}{E}
\end{aligned}
$$

where $\sigma_{\text {nom }}$ is engineering stress, $\mathcal{E}_{\text {nom }}$ is engineering strain, $\sigma_{\text {true }}$ is true stress, $\varepsilon_{\text {true }}$ is true plastic

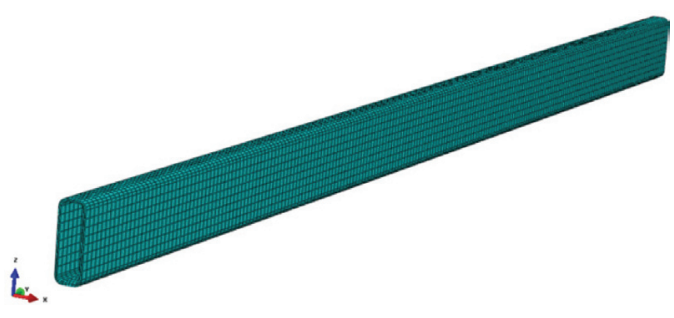

Figure 2. Mesh of numerical model.

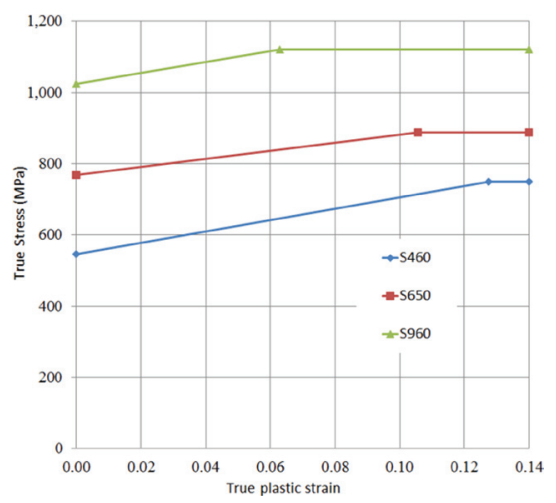

Figure 3. True stress and true plastic strain curves of the materials.

strain. Figure 3 shows true stress and true plastic strain curves of high strength materials S460, S650 and $\mathrm{S} 960$.

\section{BUCKLING ANALYSIS}

Buckling analysis is the first step of the analysis sequence. The buckling analysis is performed in order to obtain buckling shape and elastic critical moment. Figure 4 presents typical buckling shape of the numerical models. According to SN003 [10], elastic critical moment of doubly symmetric sections can calculate as follows:

$M_{c r}=C_{1} \frac{\pi^{2} E I_{z}}{L^{2}}\left\{\sqrt{\frac{I_{w}}{I_{z}}+\frac{L^{2} G I_{t}}{\pi^{2} E I_{z}}+\left(C_{2} z_{g}\right)^{2}}-C_{2} z_{g}\right\}$

where $I_{z}$ is the second moment of area about the weak axis, $I_{t}$ is the torsion constant, $I_{w}$ is warping constant, $\mathrm{L}$ is the beam length between points which have lateral restraint, $z_{g}$ is the distance between the point of load application and shear center. This equation was used for calculation of elastic critical moments of box beams in [1]. 


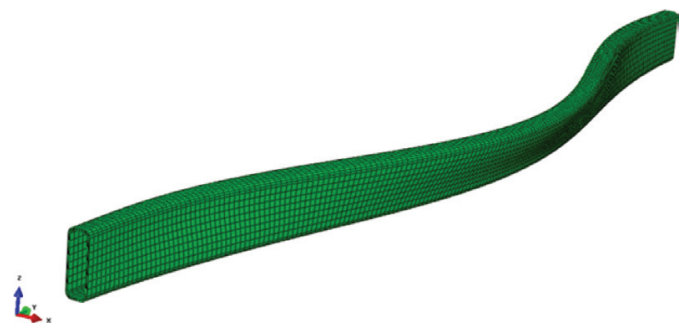

Figure 4. Typical buckling shape of numerical models.

Table 1. Elastic critical moments according to FEA and EC3.

\begin{tabular}{lcccc}
\hline & \multicolumn{4}{c}{$\begin{array}{l}\text { Elastic critical moment Mcr } \\
(\mathrm{kNm})\end{array}$} \\
\cline { 3 - 5 } Specimen & $\begin{array}{l}\text { Thickness } \\
\text { mm }\end{array}$ & FEA & SN003 & FEA/SN003 \\
\hline HRC-6 & 6 & 1330 & 1083 & 1.2 \\
HRC-8 & 8 & 1934 & 1446 & 1.3 \\
HRC-10 & 10 & 2640 & 1811 & 1.5 \\
HRC-12 & 12 & 3395 & 2179 & 1.6 \\
HRC-14 & 14 & 4173 & 2549 & 1.6 \\
\hline
\end{tabular}

Table 1 presents comparison of the elastic critical moments between Finite Element Analysis (FEA) and SN003. The FEA results are higher than those according to SN003. Elastic critical loads from FEA of the $6 \mathrm{~mm}$ and $14 \mathrm{~mm}$ thick specimens are $20 \%$ and $60 \%$ higher than those from SN003, respectively.

\section{PARAMETRIC ANALYSIS}

\subsection{Buckling resistance analysis}

According to EN1993-1-1 [11], buckling resistance moment is recommended as follows:

$$
M_{b, R d}=\chi_{L T} W_{y} \frac{f_{y}}{\gamma_{M 1}}
$$

where $W_{y}$ is the approximate section modulus as follows:

$$
\begin{array}{ll}
W_{y}=W_{p l, y} & \text { for Class } 1 \text { or } 2 \text { cross sections } \\
W_{y}=W_{\text {el, }} & \text { for Class } 3 \text { cross sections } \\
W_{y}=W_{e f f, y} & \text { for Class } 4 \text { cross sections }
\end{array}
$$

$\chi_{L T}$ is the reduction factor for lateral-torsional buckling.

According to EN 1993-1-3 [12], influence of cold forming are calculated as increasing average yield strength $f_{y a}$ in following equation: $f_{y a}=f_{y b}+\left(f_{u}-f_{y b}\right) \frac{k n t^{2}}{A_{g}}$ but $f_{y a} \leq \frac{\left(f_{u}+f_{y b}\right)}{2}$

Where $f_{v b}$ is the basic yield strength, $f_{u}$ is tensile strength, $\mathrm{Ag}$ is the gross cross sectional area, $\mathrm{k}$ is a numerical coefficient, $\mathrm{n}$ is the number of $90^{\circ}$ bends, $t$ is the thickness.

Table 2 presents resistances moments of specimens with different thicknesses and materials. Comparison between buckling resistance moments according to FEA and EC3 are also presented in this table. Resistance moments according to EC3 equal approximately $75 \%$ those according to FEA. Failure mode of $8 \mathrm{~mm}$ thick numerical models is illustrated in Figure 5.

Figure 6 presents resistance moment-rotation curves with various thicknesses $6 \mathrm{~mm}, 8 \mathrm{~mm}$, $10 \mathrm{~mm}, 12 \mathrm{~mm}$ and $14 \mathrm{~mm}$. Thickness significantly affects resistance moments of the beams. Resistance moment of the beam with $6 \mathrm{~mm}$ thickness equals $413 \mathrm{kNm}$ and reaches $995 \mathrm{kNm}$ with $14 \mathrm{~mm}$ thickness (241\%). Resistance moments

\begin{tabular}{|c|c|c|c|c|c|}
\hline \multirow[b]{2}{*}{ Specimen } & \multirow[b]{2}{*}{ Material } & \multirow{2}{*}{$\begin{array}{l}\text { Thickness } \\
(\mathrm{mm})\end{array}$} & \multicolumn{3}{|c|}{$\begin{array}{l}\text { Buckling resistance } \\
\mathrm{M}_{\mathrm{b}, \mathrm{Rd}}(\mathrm{kNm})\end{array}$} \\
\hline & & & EC3 & FEA & EC3/FEA \\
\hline \multirow[t]{2}{*}{ HRC-6 } & S460 & 6 & 183 & 233 & 0.8 \\
\hline & S650 & 6 & 237 & 316 & 0.8 \\
\hline \multirow[t]{2}{*}{ HRC-8 } & $\mathrm{S} 460$ & 8 & 246 & 327 & 0.8 \\
\hline & S650 & 8 & 317 & 428 & 0.7 \\
\hline \multirow[t]{2}{*}{ HRC-10 } & $\mathrm{S} 460$ & 10 & 311 & 396 & 0.8 \\
\hline & S650 & 10 & 397 & 532 & 0.7 \\
\hline \multirow[t]{2}{*}{ HRC-14 } & $\mathrm{S} 460$ & 14 & 444 & 580 & 0.8 \\
\hline & S650 & 14 & 558 & 755 & 0.7 \\
\hline
\end{tabular}
of the beam with $8 \mathrm{~mm}, 10 \mathrm{~mm}$ and $12 \mathrm{~mm}$ are

Table 2. Buckling resistances according to FEA and EC3.

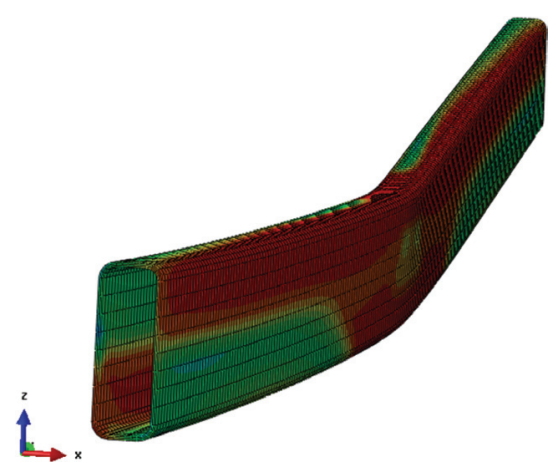

Figure 5. Failure mode of $8 \mathrm{~mm}$ thick numerical model. 


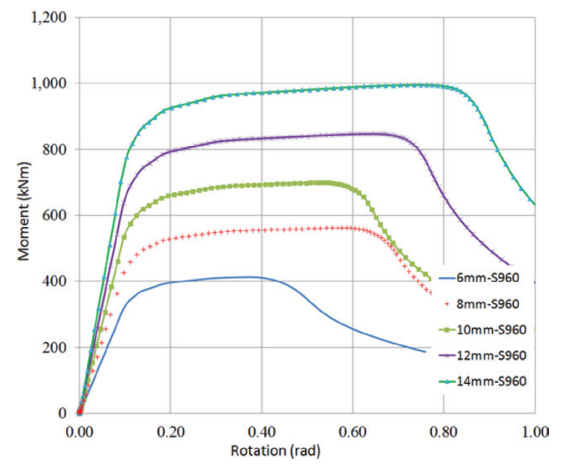

Figure 6. Influence of various thicknesses on resistance moment.

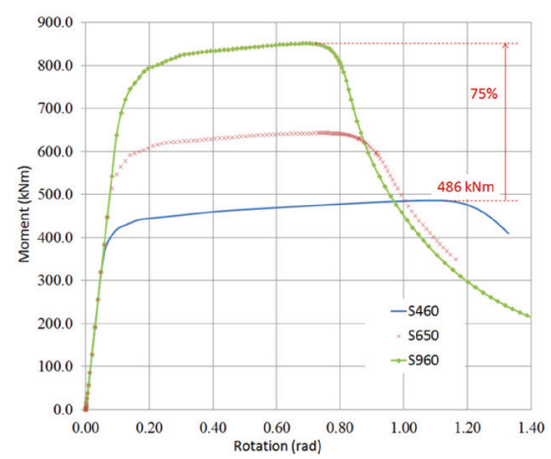

Figure 7. Influence of high strength steel on resistance moments of $12 \mathrm{~mm}$ thick numerical model.

$562 \mathrm{kNm}, 700 \mathrm{kNm}$ and $847 \mathrm{kNm}$ respectively. It must be emphasized that the material used is the high strength material S960.

\subsection{Using high strength steel}

Figure 7 illustrates resistance moment-rotation curves of the beam with $12 \mathrm{~mm}$ thick cross section with various high strength materials S460, S650 and S960. Using high strength steel considerably increase resistance moments of the beams. The resistance moment of the beam with the material S460 reaches $486 \mathrm{kNm}$. It increases $75 \%$ in using the high strength steel S960.

Applications of high strength steel on coldformed hollow sections lead to thinner and lighter structures. Resistance moment of the beam with thickness $12 \mathrm{~mm}$ using material S460 is $486 \mathrm{kNm}$. While resistance moment of the beam with thickness $8 \mathrm{~mm}$ using material $\mathrm{S} 960$ is $564 \mathrm{kNm}$. The thickness decreases approximately $33 \%$.
Table 3. Resistance moments with various geometric imperfection amplitudes.

\begin{tabular}{llllll}
\hline & \multicolumn{5}{c}{$\begin{array}{l}\text { Buckling resistance } \mathrm{M}_{\mathrm{b}, \mathrm{Rd}} \\
(\mathrm{kNm})\end{array}$} \\
\cline { 4 - 7 } Specimen & $\begin{array}{l}\text { Thickness } \\
(\mathrm{mm})\end{array}$ & $\mathrm{L} / 1000$ & $\mathrm{~L} / 750$ & $\mathrm{~L} / 500$ & $\mathrm{~L} / 250$ \\
\hline HRC-6 & 6 & 415 & 413 & 410 & 402 \\
HRC-8 & 8 & 564 & 562 & 559 & 554 \\
HRC-10 & 10 & 703 & 700 & 695 & 685 \\
HRC-12 & 12 & 851 & 847 & 841 & 830 \\
HRC-14 & 14 & 1000 & 995 & 989 & 975 \\
\hline
\end{tabular}

\subsection{Geometric imperfection sensitive analysis}

In order to investigate influence of geometric imperfection on resistance moment, amplitudes of geometric imperfections $\mathrm{L} / 1000, \mathrm{~L} / 750, \mathrm{~L} / 500$ and $\mathrm{L} / 250$ have been considered. Buckling resistance of specimens with geometric imperfection amplitudes L/1000 are higher approximately 3\% than those with geometric imperfection L/250.

\section{CONCLUSION}

In this paper, numerical investigations of lateral torsional buckling resistance of cold formed high strength steel rectangular hollow beams are presented. Buckling behaviors of the beams under constant bending moments were analyzed. Results from the analyses showed that resistance moments of the beams according to EC 3 are approximately $70 \%$ of those using FEA. Using high strength steel significantly reduces thickness of beams (approximately 33\%). Using high strength steel S960 considerably increases resistance moment $75 \%$ in comparison with using the steel material S460. The resistance moments were also affected by geometric imperfection amplitudes. Resistance moments of specimens with geometric imperfection amplitudes $\mathrm{L} / 1000$ are higher approximately $3 \%$ than those with geometric imperfection $\mathrm{L} / 250$.

\section{REFERENCES}

[1] Saoula A., Meftah S.A., Mohri F., Daya E.M., Lateral buckling of box beam elements under combined axial and bending loads, Journal of Constructional Steel Research, vol. 116, pp. 141-155.

[2] Sonck D., Belis J., Lateral buckling resistance of cellular beams, Journal of Constructional Steel Research, vol. 105, pp. 119-128.

[3] Taras A., Greiner R., New design curves for lateraltorsional buckling-Proposal based on a consistent derivation, Journal of Constructional Steel Research, vol. 66 , pp. $648-663$. 
[4] Bjorhovde R., Development and use of high performance steel, Journal of constructional steel research, vol. 60, pp. 393-400.

[5] Miki C., Homma K., Tominaga T., High strength and performence steels and their use in bridge structures, Journal of constructional steel research, vol. 58, pp. 3-20.

[6] Abaqus 6.12-1, Simulia Dassault Systmes, 2012.

[7] Wempner G.A., Discrete approximation related to nonlinear theories of solids, International Journal of Solid and Structures, vol. 7, pp. 1581-1599.

[8] Riks E., The application of Newton's method to problem of elastic stability, Journal of Applied Mechanics, vol. 39, pp. 1060-1065.

[9] Riks E., An increment approach to the solution of snapping and buckling problems, International Journal of Solid and Structures, vol. 15, pp. 529-551.

[10] SN003, NCCI: Elatic critical moment for lateral torsional buckling. www.steel-ncci.co.uk.
[11] EN 1993-1-1. Design of steel structures, Part 1-1: General rules and rules for buildings, Brussels, Belgium: European Committee for Standardization, 2005.

[12] EN 1993-1-3. Design of steel structures, Part 1-3: General rules - Supplementary rules for coldformed members and sheeting, Brussels, Belgium: European Committee for Standardization, 2006.

[13] Shi G., Zhou W., Bai Y., Lin C., Local buckling of $460 \mathrm{MPa}$ high strength steel welded section stub columns under axial compression, Journal of Constructional Steel Research, vol. 100, pp. 60-70.

[14] Tran A.T., Veljkovic M., Rebelo C., Simões da Silva L., Resistance of cold-formed high strength steel circular and polygonal sectionsPart 1: Experimental investigations, Journal of Constructional Steel Research, doi:10.1016/ j.jesr.2015.10.014. 